\title{
Front Matter: Volume 7993
}

, "Front Matter: Volume 7993," Proc. SPIE 7993, ICONO 2010: International Conference on Coherent and Nonlinear Optics, 799301 (26 January 2011); doi: $10.1117 / 12.888084$

Event: International Conference on Coherent and Nonlinear Optics (ICONO 2010) and International Conference on Lasers, Applications and Technologies 


\title{
PROCEEDINGS OF SPIE
}

\section{ICONO 2010: International Conference on Coherent and Nonlinear Optics}

\author{
Claude Fabre \\ Victor Zadkov \\ Konstantin Drabovich \\ Editors \\ 23-26 August 2010 \\ Kazan, Russian Federation \\ Organized by \\ Russian Academy of Sciences (Russian Federation) \\ M.V. Lomonosov Moscow State University (Russian Federation) \\ Zavoisky Physical-Technical Institute (Russian Federation) \\ Academy of Sciences of the Republic of Tatarstan (Russian Federation) \\ Sponsored by \\ Russian Foundation for Basic Research (Russian Federation) \\ Government of the Republic of Tatarstan (Russian Federation) \\ Optical Society of America \\ Cooperating Organizations \\ SPIE \\ IUPAP_-International Union for Pure and Applied Physics \\ Published by \\ SPIE
}

Volume 7993 
The papers included in this volume were part of the technical conference cited on the cover and title page. Papers were selected and subject to review by the editors and conference program committee. Some conference presentations may not be available for publication. The papers published in these proceedings reflect the work and thoughts of the authors and are published herein as submitted. The publisher is not responsible for the validity of the information or for any outcomes resulting from reliance thereon.

Please use the following format to cite material from this book:

Author(s), "Title of Paper," in ICONO 2010: International Conference on Coherent and Nonlinear Optics, edited by Claude Fabre, Victor Zadkov, Konstantin Drabovich, Proceedings of SPIE Vol. 7993 (SPIE, Bellingham, WA, 2011) Article CID Number.

ISSN 0277-786X

ISBN 9780819485663

Published by

SPIE

P.O. Box 10, Bellingham, Washington 98227-0010 USA

Telephone +1 3606763290 (Pacific Time) · Fax +1 3606471445

SPIE.org

Copyright (@ 2011, Society of Photo-Optical Instrumentation Engineers

Copying of material in this book for internal or personal use, or for the internal or personal use of specific clients, beyond the fair use provisions granted by the U.S. Copyright Law is authorized by SPIE subject to payment of copying fees. The Transactional Reporting Service base fee for this volume is $\$ 18.00$ per article (or portion thereof), which should be paid directly to the Copyright Clearance Center (CCC), 222 Rosewood Drive, Danvers, MA 01923. Payment may also be made electronically through CCC Online at copyright.com. Other copying for republication, resale, advertising or promotion, or any form of systematic or multiple reproduction of any material in this book is prohibited except with permission in writing from the publisher. The CCC fee code is 0277-786X/11/\$18.00.

Printed in the United States of America.

Publication of record for individual papers is online in the SPIE Digital Library.

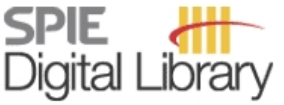

SPIEDigitalLibrary.org

Paper Numbering: Proceedings of SPIE follow an e-First publication model, with papers published first online and then in print and on CD-ROM. Papers are published as they are submitted and meet publication criteria. A unique, consistent, permanent citation identifier (CID) number is assigned to each article at the time of the first publication. Utilization of CIDs allows articles to be fully citable as soon they are published online, and connects the same identifier to all online, print, and electronic versions of the publication. SPIE uses a six-digit CID article numbering system in which:

- The first four digits correspond to the SPIE volume number.

- The last two digits indicate publication order within the volume using a Base 36 numbering system employing both numerals and letters. These two-number sets start with 00, 01, 02, 03, 04 , 05, 06, 07, 08, 09, OA, OB ... 0Z, followed by 10-1Z, 20-2Z, etc.

The CID number appears on each page of the manuscript. The complete citation is used on the first page, and an abbreviated version on subsequent pages. Numbers in the index correspond to the last two digits of the six-digit CID number. 


\section{Contents}

xiii Conference Committees

SECTION 1 FUNDAMENTALS OF NONLINEAR OPTICS AND NOVEL PHENOMENA, NONLINEAR SPACE-TIME DYNAMICS, INSTABILITIES, AND PATTERNS

799302 Phase matched conversion of radiation in nonlinear photonic crystals of strontium tetraborate [7993-01]

A. S. Aleksandrovsky, A. M. Vyunishev, A. I. Zaitsev, Kirensky Institute of Physics (Russian Federation) and Siberian Federal Univ. (Russian Federation); A. A. Ikonnikov, G. I. Pospelov, V. V. Slabko, Siberian Federal Univ. (Russian Federation)

799303 Investigation of nonlinear optical limiting and observing diffraction rings in acid blue29 [7993-02]

M. D. Zidan, Z. Ajji, Atomic Energy Commission (Syrian Arab Republic)

799304 Effect of dispersion and nonlinearity on intense femtosecond pulse propagation in GaAs/AIGaAs waveguide structure [7993-03]

A. A. Koser, Medi-Caps Institute of Technology and Management (India); P. Sen, Devli Ahilya Vishvavidyalaya (India); P. K. Sen, Shri G.S. Institute of Technology \& Science (India)

799305 Photophysical and photochemical properties of some tetrapyrrole derivatives under power laser radiation [7993-04]

E. G. Ermolina, R. T. Kuznetsova, Tomsk State Univ. (Russian Federation); N. Rusakova, Yu. V. Korovin, Bogatskii Physicochemical Institute (Ukraine); S. M. Arabei, Belorussian Agrarian-Technical State Univ. (Belarus); T. A. Pavich, B.I. Stepanov Institute of Physics (Belarus)

799306 Ultrashort UV pulse generation by four-wave mixing through filamentation [7993-05] T. Fuji, RIKEN (Japan), Japan Science and Technology Agency, CREST (Japan), and Institute for Molecular Science (Japan); P. Zuo, RIKEN (Japan) and Japan Science and Technology Agency, CREST (Japan); T. SuzUki, RIKEN (Japan), Japan Science and Technology Agency, CREST (Japan), and Kyoto Univ. (Japan)

799307 Second-order nonlinear optical response of the epoxy-based thin films with azochromophores [7993-06]

T. A. Vakhonina, S. M. Sharipova, N. V. Ivanova, O. D. Fominykh, A.E. Arbuzov Institute of Organic and Physical Chemistry (Russian Federation); N. N. Smirnov, Institute of Macromolecular Compounds (Russian Federation); A. V. Yakimansky, Institute of Macromolecular Compounds (Russian Federation) and A.E. Arbuzov Institute of Organic and Physical Chemistry (Russian Federation); M. Yu. Balakina, A.E. Arbuzov Institute of Organic and Physical Chemistry (Russian Federation) and Institute of Macromolecular Compounds (Russian Federation) 
799308 On nonlinear reflection of optical pulse from low-frequency few cycle pulse [7993-07] A. N. Bugay, Joint Institute for Nuclear Research (Russian Federation); S. V. Sazonov, Russian Research Ctr. Kurchatov Institute (Russian Federation); A. P. Sukhorukov, Moscow State Univ. (Russian Federation)

799309 Hyper-Raman effect treatment in a rutile crystal [7993-08]

L. E. Semenova, K. A. Prokhorov, A.M. Prokhorov General Physics Institute (Russian Federation)

7993 OA Optical bistability in nonlinear system with two loops of feedback [7993-09] G. P. Miroshnichenko, A. I. Trifanov, Saint-Petersburg State Univ. of Information Technologies, Mechanics and Optics (Russian Federation)

7993 OB Self-induced polarization rotation of laser beam in fullerene $\left(\mathrm{C}_{\mathbf{7 0}}\right)$ solutions [7993-10] S. A. Bakhramov, Akadempribor Scientific-Production Association (Uzbekistan); A. M. Kokharov, Academy of Sciences (Uzbekistan); U. K. Makhmanov, R. Kokharov, Akadempribor Scientific-Production Association (Uzbekistan)

7993 OC The change of spectral characteristics of amino acids dependent upon the influence of powerful laser radiation [7993-11]

E. S. Gladyshev, S. A. Kutsenko, V. N. Khramov, E. A. Ilina, A. I. Stepanova, Volgograd State Univ. (Russian Federation)

7993 OD The collective elementary excitations of 2D magnetoexcitons in the BEC state with wave vector $\mathbf{k}=\mathbf{0}$ [7993-12]

S. A. Moskalenko, Institute of Applied Physics (Moldova); M. A. Liberman, Uppsala Univ. (Sweden); E. V. Dumanov, Institute of Applied Physics (Moldova)

7993 OE Four-wave mixing theory for two-photon generation of excitons in thin films of cuprous oxide [7993-13]

I. V. Beloussov, Institute of Applied Physics (Moldova); J. B. Ketterson, Y. Sun, Northwestern Univ. (United States)

7993 OF Nonlinear transmission of ultrashort laser pulses by a thin semiconductor film under twophoton generation of biexcitons [7993-14]

I. V. Beloussov, Institute of Applied Physics (Moldova); P. I. Khadzhi, Institute of Applied Physics (Moldova) and Dniester State Univ. (Moldova); A. V. Corovai, D. A. Markov, Dniester State Univ. (Moldova)

7993 OG Transmission of phase modulated laser light through a thin semiconductor film in the excitonic spectral range and an optical analog of the Feshbach effect [7993-15] P. I. Khadzhi, Institute of Applied Physics (Moldova) and Dniester State Univ. (Moldova); I. V. Beloussov, Institute of Applied Physics (Moldova); N. N. Rosanov, S. V. Fedorov, Vavilov State Optical Institute (Russian Federation); A. V. Corovai, D. A. Markov, Dniester State Univ. (Moldova) 
$7993 \mathrm{OH} \quad$ Nonlinear optical properties of gold nanoparticles thin films using the moire deflectometery technique [7993-16]

A. GranmayehRad, Islamic Azad Univ. (Iran, Islamic Republic of); K. Madanipour, Amirkabir Univ. of Technology (Iran, Islamic Republic of); M. H. Afzali, Islamic Azad Univ. (Iran, Islamic Republic of); A. Koohian, Tehran Univ. (Iran, Islamic Republic of); D. Dorranian, Islamic Azad Univ. (Iran, Islamic Republic of)

7993 Ol Temporal shaping of ultrashort laser pulses by volumetric chirped Bragg gratings [7993-17] A. A. Manenkov, A.M. Prokhorov General Physics Institute (Russian Federation); A. A. Muraviev, Institute of Applied Physics (Russian Federation); A. V. Smirnov, E. V. Shashkov, N. S. Vorobiev, A.M. Prokhorov General Physics Institute (Russian Federation)

$79930 \mathrm{~J}$ The plasma gamma ray laser creation and first gamma holograms production [7993-18] V. Skvortsov, Moscow Institute for Physics and Technology (Russian Federation); N. Vogel, Technische Univ. Chemnitz (Germany)

7993 OK Reversible nonlinear absorption in nanoporous glass polymer composite doped with functional dyes: experiment and background model [7993-19]

L. M. Koldunov, Moscow Institute of Physics and Technology (State Univ.) (Russian Federation); M. F. Koldunov, A.M. Prokhorov General Physics Institute (Russian Federation); A. V. Petuhov, P.N. Lebedev Physical Institute (Russian Federation); A. V. Sizuhin, Moscow Institute of Physics and Technology (State Univ.) (Russian Federation)

$7993 \mathrm{OL} \quad$ Harmonics generation by mixing of s-wave with metal-heating wave [7993-20] S. G. Bezhanov, S. A. Uryupin, P.N. Lebedev Physical Institute (Russian Federation)

7993 OM Nonlinear refraction and nonlinear absorption in nanoporous glass composite activated by functional dyes [7993-21]

L. M. Koldunov, Moscow Institute of Physics and Technology (State Univ.) (Russian Federation); M. F. Koldunov, A.M. Prokhorov General Physics Institute (Russian Federation); A. V. Petuhov, P.N. Lebedev Physical Institute (Russian Federation); I. L. Pokotilo, A. V. Sizuhin, Moscow Institute of Physics and Technology (State Univ.) (Russian Federation)

7993 ON Optical properties of the two-dimensional magnetoexcitons under the influence of the Rashba spin-orbit coupling [7993-22]

T. Hakioglu, Bilkent Univ. (Turkey); M. A. Liberman, Uppsala Univ. (Sweden); S. A. Moskalenko, I. V. Podlesny, Institute of Applied Physics (Moldova)

$799300 \quad$ New nonlinear phenomena under conditions of strong selective reflection [7993-23] Ya. A. Fofanov, Institute for Analytical Instrumentation (Russian Federation)

7993 OP Ultrashort pulse sources in the mid-IR [7993-24]

J. Biegert, ICFO - Instituto de Ciències Fotòniques (Spain) and ICREA - Institució Catalana de Recerca i Estudis Avançats (Spain); O. Chalus, P. Bates, A. Thai, ICFO - Instituto de Ciències Fotòniques (Spain)

$79930 Q \quad$ Multicolor nonlinear pulse compression by consecutive optical parametric amplification in quasi-phase matched structures [7993-25]

U. K. Sapaev, Institute of Electronics (Uzbekistan); D. B. Yusupov, Tashkent State Technical Univ. (Uzbekistan); G. Assanto, Univ. degli Studi di Roma Tre (Italy) 
7993 OR Application of the longitudinal electro-optical effect in KD*P for detection of a Doppler shift of the wave frequency at reflection from the high-temperature laser plasma [7993-26] B. V. Anikeev, M. A. Fedotova, I. V. Kas'yanov, V. N. Khramov, N. V. Solosov, Volgograd State Univ. (Russian Federation)

7993 OS Laser cavity round trip time scale regular and chaotic nonlinear dynamics in a picosecond laser controlled with a combination of positive and negative optoelectronic feedbacks [7993-27]

K. A. Bubnov, M. V. Gorbunkov, S. M. Kutuzov, Yu. Ya. Maslova, V. A. Petukhov, M. A. Semenov, Yu. V. Shabalin, P.N. Lebedev Physical Institute (Russian Federation)

7993 OT Optical properties of semiconductors in exciton range of spectrum in non-stationary regime taking into account the exciton-exciton interaction [7993-28]

P. I. Khadzhi, Institute of Applied Physics (Moldova); L. Yu. Nadkin, Dniester State Univ. (Moldova)

7993 OU Anomalous thermalization of optical waves induced by third-order dispersion effects [7993-29]

C. Michel, Institut Carnot de Bourgogne, CNRS, Univ. de Bourgogne (France); S. Randoux, P. Suret, Lab. PhLAM, CNRS, Univ. de Lille (France); A. Picozzi, Institut Carnot de Bourgogne, CNRS, Univ. de Bourgogne (France)

7993 OV Low threshold Raman laser [7993-30]

M. G. Galushkin, Institute on Laser and Information Technologies (Russian Federation); K. V. Mitin, A. M. Seryogin, SPA Astrophysica (Russian Federation)

7993 OW Absolute instability of phase conjugation at four-wave mixing in SBS media [7993-31] M. G. Galushkin, Institute of Problems of Laser and Information Technologies (Russian Federation); K. V. Mitin, A. M. Seryogin, SPA Astrophysica (Russian Federation)

SECTION 2 QUANTUM AND ATOM OPTICS; QUANTUM PHYSICS, INFORMATION, AND TECHNOLOGIES

7993 0X Decay, excitation, and ionization of lithium Rydberg states by blackbody radiation [7993-32]

V. D. Ovsiannikov, I. L. Glukhov, Voronezh State Univ. (Russian Federation)

7993 OY Progress toward a precision measurement of the atomic recoil frequency using an echotype atom interferometer [7993-33]

B. Barrett, S. Beattie, A. Carew, I. Chan, C. Mok, York Univ. (Canada); I. Yavin, New York Univ. (United States) A. Kumarakrishnan, York Univ. (Canada)

$79930 Z$ Photon echo locking via inhomogeneous broadening controlled by a weak pulsed magnetic field and optical storage [7993-34]

D. A. Khristoforova, Kazan Federal Univ. (Russian Federation); A. A. Kalachev, A. M. Shegeda, Zavoisky Physical-Technical Institute (Russian Federation)

799310 Teleportation of entangled images with multiwave nonlinear optical interactions [7993-35] M. Yu. Saygin, M.V. Lomonosov Moscow State Univ. (Russian Federation) and Univ. de Lille 1 (France); A. S. Chirkin, M.V. Lomonosov Moscow State Univ. (Russian Federation); M. I. Kolobov, Univ. de Lille 1 (France) 
799311 Atomic photomicroscope in the Coulomb field [7993-36]

P. A. Golovinski, A. A. Drobyshev, Voronezh State Univ. of Architecture and Construction (Russian Federation)

799312 Magneto-optical CPT resonances in rubidium excited by femtosecond laser comb [7993-37]

R. A. Malitskiy, V. M. Khodakovskiy, A. M. Negriyko, V. I. Romanenko, I. V. Matsnev,

L. P. Yatsenko, Institute of Physics (Ukraine)

799313 Trapping Rydberg atoms in optical lattices [7993-38]

G. Raithel, K. C. Younge, S. E. Anderson, Univ. of Michigan (United States); B. Knuffman, National Institute of Standards and Technology (United States)

799314 Resonance collisions of ultracold polar molecules in a microwave field [7993-39]

A. Avdeenkov, National Institute for Theoretical Physics (South Africa) and Moscow State Univ. (Russian Federation)

799315 Frequency-modulation spectroscopy of coherent dark resonances of multilevel atoms in magnetic field [7993-40]

Yu. V. Vladimirova, V. N. Zadkov, M.V. Lomonosov Moscow State Univ. (Russian Federation)

799316 Modeling dynamics of atoms in a femtosecond optical dipole trap [7993-41]

I. S. Tarakanov, M.V. Lomonosov Moscow State Univ. (Russian Federation); V. I. Balykin, Institute of Spectroscopy (Russian Federation); Yu. V. Vladimirova, D. N. Yanyshev,

V. N. Zadkov, M.V. Lomonosov Moscow State Univ. (Russian Federation)

SECTION 3 HIGH-FIELD PHYSICS AND HIGH-INTENSITY LASERS; SYMPOSIUM ON FEMTOSECOND LASER PULSE FILAMENTATION; ULTRAFAST PHENOMENA AND HIGH-PRECISION MEASUREMENTS

799317 Development of a 100-terawatt hybrid femtosecond laser system [7993-42]

V. Losev, S. Alekseev, N. Ivanov, B. Kovalchuk, Institute of High Current Electronics (Russian Federation); L. Mikheev, G. Mesyats, P.N. Lebedev Physical Institute (Russian Federation);

Yu. Panchenko, A. Puchikin, N. Ratakhin, A. Yastremsky, Institute of High Current Electronics (Russian Federation)

799318 Diagnostics of the peak laser intensity based on the measurement of energy spectra of electrons accelerated by the laser beam [7993-43]

A. L. Galkin, A.M. Prokhorov General Physics Institute (Russian Federation); M. P. Kalashnikov, Max-Born-Institute for Nonlinear Optics and Short-time Spectroscopy (Germany);

V. V. Korobkin, A.M. Prokhorov General Physics Institute (Russian Federation) and Moscow Institute of Physics and Technology (State Univ.) (Russian Federation); M. Yu. Romanovsky, O. B. Shiryaev, V. A. Trofimov, A.M. Prokhorov General Physics Institute (Russian Federation)

799319 Emission of zeptosecond electromagnetic pulses by an electron driven by a relativistically intense laser field [7993-44]

A. L. Galkin, A.M. Prokhorov General Physics Institute (Russian Federation); V. V. Korobkin, A.M. Prokhorov General Physics Institute (Russian Federation) and Moscow Institute of Physics and Technology (State Univ.) (Russian Federation); M. Yu. Romanovsky,

O. B. Shiryaev, A.M. Prokhorov General Physics Institute (Russian Federation) 
79931 A Nonlinear Thomson scattering of the ultrashort laser pulses [7993-45]

P. A. Golovinski, E. A. Mikhin, Voronezh State Univ. of Architecture and Construction (Russian Federation)

7993 1B Laser filamentation in chalcogenide glass [7993-46]

P. Masselin, D. Le Coq, E. Bychkov, Lab. Physico Chimie de l'Atmosphère, CNRS, Univ. du Littoral Côte d'Opale (France); E. Lépine, C. Lin, L. Calvez, Sciences Chimiques de Rennes, CNRS, Univ. de Rennes 1 (France)

7993 1C Interaction of femtosecond filaments in sapphire [7993-47]

I. Blonskyi, V. Kadan, Institute of Physics (Ukraine); O. Shpotyuk, Scientific Research Co. Carat (Ukraine) and Jan Dlugosz Univ. in Czestochowa (Poland); P. Korenyuk, I. Pavlov, Institute of Physics (Ukraine)

7993 1D Novel schemes of proton acceleration at 1 PW laser power [7993-48]

A. V. Brantov, V. Yu. Bychenkov, P.N. Lebedev Physical Institute (Russian Federation)

7993 IE Photo-cycle dynamics of LOV1-His domain of phototropin from Chlamydomonas reinhardtii with roseoflavin monophosphate cofactor [7993-49]

A. Tyagi, A. Penzkofer, Univ. Regensburg (Germany); T. Mathes, P. Hegemann, Humboldt Univ. zu Berlin (Germany)

7993 IF Ultrafast microlocalized photoelectron bunches: formation and applications [7993-50] S. A. Aseyev, B. N. Mironov, V. G. Minogin, S. V. Chekalin, Institute of Spectroscopy (Russian Federation)

7993 IG The laser photocathode emitting the polarized electrons [7993-51]

B. V. Anikeev, V. N. Khramov, V. E. Markova, V. P. Tushkanov, Volgograd State Univ. (Russian Federation)

7993 1H High sensitivity rotation measurements with a mid-size laser gyroscope [7993-52]

J. Belfi, Univ. di Pisa (Italy); N. Beverini, Univ. di Pisa (Italy) and INFN (Italy); F. Bosi, INFN (Italy);

G. Carelli, Univ. di Pisa (Italy); A. Di Virgilio, INFN (Italy); E. Maccioni, Univ. di Pisa (Italy);

R. Passaquieti, F. Stefani, Univ. di Pisa (Italy) and INFN (Italy)

799311 Absolute frequency measurement of unstable lasers with optical frequency combs [7993-53]

N. Beverini, Univ. di Pisa (Italy); N. Poli, INFN, Univ. di Firenze (Italy); D. Sutyrin, Univ. di Pisa (Italy) and INFN, Univ. di Firenze (Italy); F.-Y. Wang, M. Schioppo, M. G. Tarallo, G. M. Tino, INFN, Univ. di Firenze (Italy)

7993 i U Ultrafast dynamics of crystalline bismuth studied by femtosecond pulses in visible and nearinfrared range [7993-54]

A. A. Melnikov, Institute of Spectroscopy (Russian Federation) and Moscow Institute of Physics and Technology (Russian Federation); O. V. Misochko, Institute of Solid State Physics (Russian Federation); S. V. Chekalin, Institute of Spectroscopy (Russian Federation) 
7993 IK Muonic hydrogen spectroscopy: the proton radius puzzle [7993-55]

A. Antognini, Max-Planck-Institut für Quantenoptik (Germany) and ETH Zürich (Switzerland); F. Nez, Lab. Kastler Brossel, École Normale Supérieure, CNRS (France) and Univ. Pierre et Marie Curie (France); F. D. Amaro, Univ. de Coimbra (Portugal); F. Biraben, Lab. Kastler Brossel, École Normale Supérieure, CNRS (France) and Univ. Pierre et Marie Curie (France); J. M. R. Cardoso, Univ. de Coimbra (Portugal); D. S. Covita, Univ. de Coimbra (Portugal) and Univ. de Aveiro (Portugal); A. Dax, S. Dhawan, Yale Univ. (United States); L. M. P. Fernandes, Univ. de Coimbra (Portugal); A. Giesen, Dausinger \& Giesen GmbH (Germany); T. Graf, Univ. Stuttgart (Germany); T. W. Hänsch, Max-Planck-Institut für Quantenoptik (Germany) and Ludwig-Maximilians-Univ. München (Germany); P. Indelicato, L. Julien, Lab. Kastler Brossel, École Normale Supérieure, CNRS (France) and Univ. Pierre et Marie Curie (France); C.-Y. Kao, National Tsing Hua Univ. (Taiwan); P. Knowles, Univ. de Fribourg (Switzerland); F. Kottmann, ETH Zürich (Switzerland); E.-O. Le Bigot, Lab. Kastler Brossel, École Normale Supérieure, CNRS (France) and Univ. Pierre et Marie Curie (France); Y.-W. Liu, National Tsing Hua Univ. (Taiwan); J. A. M. Lopes, Univ. de Coimbra (Portugal); L. Ludhova, Univ. de Fribourg (Switzerland); C. M. B. Monteiro, Univ. de Coimbra (Portugal); F. Mulhauser, Univ. de Fribourg (Switzerland); T. Nebel, Max-Planck-Institut für Quantenoptik (Germany);

P. Rabinowitz, Princeton Univ. (United States); J. M. F. dos Santos, Univ. de Coimbra (Portugal); L. A. Schaller, Univ. de Fribourg (Switzerland); K. Schuhmann, Dausinger \& Giesen GmbH (Germany); C. Schwob, Lab. Kastler Brossel, École Normale Supérieure, CNRS (France) and Univ. Pierre et Marie Curie (France); D. Taqqu, Paul Scherrer Institut (Switzerland); J. F. C. A. Veloso, Univ. de Aveiro (Portugal); R. Pohl, Max-Planck-Institut für Quantenoptik (Germany)

SECTION 4 NANOPHOTONICS AND PLASMONICS; PHYSICS OF METAMATERIALS, PERIODIC AND RANDOM MEDIA; SYMPOSIUM ON PHOTOVOLTAICS; SYMPOSIUM ON THZ TECHNOLOGIES AND APPLICATIONS

7993 IL Non-linear optical property of nanocomposite CdS [7993-56]

I. G. Galyaviev, G. M. Safiullin, V. G. Nikiforov, V. S. Lobkov, I. M. Nassar,

U. G. Galyametdinov, Kazan Physical-Technical Institute (Russian Federation)

$79931 \mathrm{M}$ Reversible and irreversible structural transformations of nanocomponents of molecular layers by resonance photoexcitation or heating [7993-57]

E. N. Kaliteevskaya, V. P. Krutyakova, T. K. Razumova, A. A. Starovoytov, Saint-Petersburg State Univ. of Information Technologies, Mechanics and Optics (Russian Federation)

7993 iN Chiral photonic bandgap microcavities doped with single colloidal semiconductor quantum dots [7993-58]

L. J. Bissell, S. G. Lukishova, The Institute of Optics, Univ. of Rochester (United States);

A. W. Schmid, M. A. Hahn, C. M. Evans, T. D. Krauss, Univ. of Rochester (United States);

C. R. Stroud, Jr., R. W. Boyd, The Institute of Optics, Univ. of Rochester (United States)

799310 Room-temperature single photon sources with definite circular and linear polarizations based on single-emitter fluorescence in liquid crystal hosts [7993-59]

L. J. Bissell, S. G. Lukishova, The Institute of Optics, Univ. of Rochester (United States);

A. W. Schmid, M. A. Hahn, C. M. Evans, T. D. Krauss, Univ. of Rochester (United States);

C. R. Stroud, Jr., R. W. Boyd, The Institute of Optics, Univ. of Rochester (United States) 
7993 IP Composite medium with silver nanoparticles for anti-reflection coating application [7993-60]

S. G. Moiseev, Kotelnikov Institute of Radio Engineering and Electronics (Russian Federation), Ulyanovsk State Univ. (Russian Federation), and Ulyanovsk State Technical Univ. (Russian Federation); S. V. Vinogradov, A. A. Kulikov, Ulyanovsk State Technical Univ. (Russian Federation)

$79931 Q \quad$ Nanosized plasmonic polarizer [7993-61]

S. G. Moiseev, Kotelnikov Institute of Radio Engineering and Electronics (Russian Federation), Ulyanovsk State Univ. (Russian Federation), and Ulyanovsk State Technical Univ. (Russian Federation)

7993 IR State-filling and self-action processes at resonant excitation of excitons in colloidal quantum dots [7993-62]

V. Dneprovskii, M. Kozlova, T. Wumaier, E. Zhukov, S. H. Dau, A. Smirnov, M.V. Lomonosov Moscow State Univ. (Russian Federation)

7993 is The excitation of vibrational wave packets in chloroform by femtosecond pulses: effect of gold nanoparticles [7993-63]

A. Kostrov, A. Aiboushev, F. Gostev, I. Shelaev, O. Sarkisov, N.N. Semenov Institute of Chemical Physics (Russian Federation); N. Denisov, D. Khudyakov, Institute of Problems of Chemical Physics (Russian Federation); V. Nadtochenko, N.N. Semenov Institute of Chemical Physics (Russian Federation) and Institute of Problems of Chemical Physics (Russian Federation)

7993 IT Nanophotonics and nanoplasmonics elements produced by atom optics methods [7993-64]

P. N. Melentiev, A. E. Afanasiev, D. A. Lapshin, Institute of Spectroscopy (Russian Federation); A. V. Zablotskiy, A. A. Kuzin, A. S. Baturin, Moscow Institute of Physics and Technology (Russian Federation); V. I. Balykin, Institute of Spectroscopy (Russian Federation)

$79931 \mathrm{U} \quad$ ZnO complex structures: laser spectra analysis [7993-65]

V. M. Markushev, M. V. Ryzhkov, Ch. M. Briskina, A. A. Borodkin, Kotel'nikov Institute of Radio Engineering and Electronics (Russian Federation)

$79931 \mathrm{~V}$ Two-photon luminescence as a probe of local field enhancement in hot spot of plasmonic nanoparticles in titanium dioxide matrix [7993-66]

A. Aiboushev, A. Astafiev, N.N. Semenov Institute of Chemical Physics (Russian Federation); Yu. Lozovik, Institute of Spectroscopy (Russian Federation); O. Sarkisov, N.N. Semenov Institute of Chemical Physics (Russian Federation); V. Nadtochenko, N.N. Semenov Institute of Chemical Physics (Russian Federation) and Institute of Problems of Chemical Physics (Russian Federation)

$79931 \mathrm{~W} \quad$ Numerical investigation of the excitation of surface plasmon polariton on a periodic surface nanograting composed of metallic nanowires [7993-67]

A. V. Andreev, A. A. Konovko, I. R. Prudnikov, M.V. Lomonosov Moscow State Univ. (Russian Federation) 
$79931 \mathrm{X}$ Controlling the light transmission through periodic and random metamaterials by applying a magnetic field and by changing the nano-structures shapes [7993-68]

Y. M. Strelniker, Bar-Ilan Univ. (Israel); D. J. Bergman, Tel Aviv Univ. (Israel); Y. Fleger,

M. Rosenbluh, Bar-Ilan Univ. (Israel); A. O. Voznesenskaya, Saint-Petersburg State Univ. of Information Technologies, Mechanics and Optics (Russian Federation); A. P. Vinogradov, A. N. Lagarkov, A. M. Merzlikin, Institute for Theoretical and Applied Electromagnetics (Russian Federation)

7993 IY Optical properties of metal nanoparticles [7993-69]

A. L. Stepanov, V. I. Nuzhdin, V. F. Valeev, Zavoisky Physical-Technical Institute (Russian Federation); U. Kreibig, RWTH Aachen (Germany)

799312 Ion synthesis and nonlinear properties of metal nanoparticles [7993-70]

A. L. Stepanov, Zavoisky Physical-Technical Institute (Russian Federation)

799320 Raman and infrared spectroscopy of organic electronic devices [7993-71]

Y. Furukawa, Waseda Univ. (Japan)

799321 Estimation of the concentration of deep traps in organic photoconductors using two-photon absorption [7993-72]

S. V. Novikov, A. R. Tameev, A. V. Vannikov, A.N. Frumkin Institute of Physical Chemistry and Electrochemistry (Russian Federation); J.-M. Nunzi, Queen's Univ. (Canada)

799322 Terahertz emission from semiconductors due to the lateral surface photocurrent [7993-73] P. A. Ziaziulia, Belarusian State Univ. (Belarus); V. L. Malevich, Institute of Physics (Belarus); I. S. Manak, Belarusian State Univ. (Belarus)

799323 Resonant generation of terahertz radiation in anisotropic media with permanent dipole moment [7993-74]

A. N. Bugay, Joint Institute for Nuclear Research (Russian Federation); S. V. Sazonov, Russian Research Ctr. Kurchatov Institute (Russian Federation)

799324 Control over the parameters of THz waves interacting with semiconductor free carriers [7993-75]

E. V. Moiseenko, Nuclear Safety Institute (Russian Federation); A. V. Shepelev, Gubkin Russian State Univ. (Russian Federation)

799325 EPR study of the effect of terahertz radiation on the albumin conformation dynamics [7993-76]

E. F. Nemova, O. P. Cherkasova, V. I. Fedorov, Institute of Laser Physics (Russian Federation)

799326 Electronic properties and influence of doping on GaSe crystal nonlinear optical parameters for the applications in terahertz range [7993-77]

M. M. Nazarov, M.V. Lomonosov Moscow State Univ. (Russian Federation); A. V. Kosobutsky, Kemerovo State Univ. (Russian Federation); S. Yu. Sarkisov, V. N. Brudnyi, O. P. Tolbanov, Tomsk State Univ. (Russian Federation); A. P. Shkurinov, M.V. Lomonosov Moscow State Univ. (Russian Federation) 
799327 Influence of THz radiation on early phase of seed germinating and yield of wheat [7993-78] V. I. Fedorov, Institute of Laser Physics (Russian Federation); G. F. Bakharev, Siberian Institute of Mechanization and Electrification of Agriculture (Russian Federation)

799328 Terahertz time-domain spectroscopy setup based on InAs emitter [7993-79]

G. V. Sinitsyn, A. V. Lyakhnovich, V. L. Malevich, N. S. Kazak, B. A. Bushuk, S. B. Bushuk, B.I. Stepanov Institute of Physics (Belarus)

Author Index 


\title{
ICONO/LAT 2010 Committees
}

\author{
General Chairs
}

Sergey Bagayev, Institute of Laser Physics (Russian Federation)

Gerd Leuchs, Max-Planck-Institut für die Physik des Lichts (Germany)

General Vice-Chair

Vladimir Makarov, M.V. Lomonosov Moscow State University (Russian Federation)

ICONO Program Chairs

Claude Fabre, Université Pierre et Marie Curie (France)

Victor N. Zadkov, M.V. Lomonosov Moscow State University (Russian Federation)

ICONO Program Vice-Chair

Konstantin Drabovich, M.V. Lomonosov Moscow State University

(Russian Federation)

ICONO Program Secretary

Masha Drabovich, M.V. Lomonosov Moscow State University (Russian Federation)

ICONO Program Subcommittees

Fundamentals of Nonlinear Optics and Novel Phenomena

Andrey Fedotov, Cochair, M.V. Lomonosov Moscow State University (Russian Federation)

Reinhard Kienberger, Cochair, Technical Universität Munich

(Germany) Andrius Baltushka, Technical Universität Wien (Austria)

Valentin Orlovich, B.I. Stepanov Institute of Physics (Belarus)

Chi-Kuang Sun, National Taiwan University (Taiwan)

Vladislav Yakovlev, University of Wisconsin-Milwaukee (United States)

Hideaki Kano, The University of Tokyo (Japan)

Nonlinear Space-Time Dynamics, Instabilities, and Patterns

Gaetano Assanto, Cochair, Universitá degli Studi Roma Tre (Italy)

Nikolay Rosanov, Cochair, Research Institute for Laser Physics (Russian Federation)

Yuri Kivshar, The Australian National University (Australia) 
Anatoly Sukhorukov, M.V. Lomonosov Moscow State University

(Russian Federation)

Stefania Residori, INLN-Université de Nice-Sophia Antipolis (France)

Frank Wise, Cornell University (United States)

Stefan Wabnitz, Universitá degli Studi di Brescia (Italy)

John Dudley, Université Franche-Comte (France)

Jorge Tredicce, INLN-Université de Nice-Sophia Antipolis (France)

Sergei Turitsyn, Aston University (United Kingdom)

Quantum and Atom Optics

Victor Balykin, Cochair, Institute of Spectroscopy (Russian Federation)

Martial Ducloy, Cochair, Université Paris-Nord 13 (France)

Sergey Kilin, B.I. Stepanov Institute of Physics (Belarus)

Valery Yudin, Institute of Laser Physics (Russian Federation)

Vladimir Minogin, Institute of Spectroscopy (Russian Federation)

Vladimir Velichanky, P.N. Lebedev Institute of Physics (Russian Federation)

Fujio Shimizu, University of Electro-Communications (Japan)

Dieter Meschede, Universität Bonn (Germany)

John Weiner, National Institute for Standards and Technologies (United States)

Paul Berman, University of Michigan (United States)

Quantum Physics, Information, and Technologies

Jeremy O'Brien, Cochair, University of Bristol (United Kingdom)

Sergey Kulik, Cochair, M.V. Lomonosov Moscow State University (Russian Federation)

Konrad Banaszek, Uniwersytet Mikołaja Kopernika (Poland)

Elisabeth Giacobino, Université Pierre et Marie Curie (France)

Marco Genovese, Institute Elettrotechnico Nazionale (Italy)

Paolo Mataloni, Universitá degli Studi di Roma La Sapienza (Italy)

Gershon Kurizki, Weizmann Institute of Science (Israel)

Maciej Lewenstein, Institute of Science and Photonics (Spain)

Zdenek Hradil, Palacký University (Poland)

High-Field Physics and High-Intensity Lasers

Wilhelm Becker, Cochair, Max-Born-Institut (Germany)

Jens Biegert, Cochair, The Institute of Photonic Sciences (Spain)

Mikhail Fedorov, Cochair, A.M. Prokhorov General Physics Institute (Russian Federation)

Louis DiMauro, The Ohio State University (United States)

Hans-Joerg Kull, Aachen University (Germany)

Pascal Salieres, Centre d'Etudes de Saclay (France)

L. Roso, Universidad de Salamanca (Spain)

Sandro De Silvestri, Politecnico di Milano (Italy)

Alexander Pukhov, Max-Planck-Institut für Quantenoptik (Germany) 
Andrey Saveliev, M.V. Lomonosov Moscow State University (Russian Federation)

Alexander Sergeev, Institute of Applied Physics (Russian Federation)

Nanophotonics and Plasmonics

Vasily Klimov, Cochair, P.N. Lebedev Physical Institute (Russian

Federation)

Vladimir Shalaev, Cochair, Purdue University (United States)

Boris Chichkov, Laser Zentrum Hanover e.V. (Germany)

Stefan Maier, Imperial College London (United Kingdom)

Anatoly Zayats, The Queen's University of Belfast (United Kingdom)

Sergey Bozhevolnyi, Aalborg University (Denmark)

Vitaly Samartsev, Zavoisky Physical-Technical Institute (Russian

Federation)

Igor Smolyaninov, University of Maryland (United States)

Din-Ping Tsai, National Taiwan University (Taiwan)

Yuri Lozovik, Institute of Spectroscopy (Russian Federation)

Sergey Gaponenko, Institute of Molecular and Atomic Physics (Belarus)

Physics of Metamaterials, Periodic, and Random Media

Nikolay Zheludev, Chair, University of Southampton (United Kingdom)

Mikhail Noginov, Norfolk State University (United States)

Natasha Litchinitser, University at Buffalo (United States)

Sergei Tikhodeev, A.M. Prokhorov General Physics Institute (Russian Federation)

Ekaterina Shamonina, Friedrich-Alexander-Universität ErlangenNürnberg (Germany)

Eugene Kamenetskii, Ben-Gurion University (Israel)

Alexandra Boltasseva, Purdue University (United States)

Allan Boardman, University of Salford (United Kingdom)

Said Zouhdi, Laboratoire de Génie Électrique de Paris, LGEP-Supelec (France)

Dorota Pawlak, Instytut Technologii Materiałów Elektronicznych

(Poland)

Lei Zhou, Fudan University (China)

Dutta Gupta, University of Hyderabad (India)

Ultrafast Phenomena and High-Precision Measurements

Nikolay Kolachevsky, Cochair, P.N. Lebedev Physical Institute (Russian Federation)

Eberhard Riedle, Cochair, Ludwig-Maximilians-Universität München (Germany)

Mikhail Gubin, P.N. Lebedev Physical Institute (Russian Federation)

Vitaly Ovsyannikov, Voronezh State University (Russian Federation)

Andrey Goncharov, Institute of Laser Physics (Russian Federation)

Alexey Taichenachev, Institute of Laser Physics (Russian Federation) 
Ekkehard Peik, Physikalisch-Technische Bundesanstalt (Germany)

Georgio Santarelli, Observatoire de Paris (France) and CNRS (France)

Frank Noack, Max-Born Institut (Germany)

Michael Woerner, Max-Born Institut (Germany)

Christian Bressler, Ecole Polytechnique Fédérale de Lausanne (Switzerland)

Taiha Joo, Pohang University of Science and Technology (Korea,

Republic of)

Algis Piskarskas, Vilnius University (Lithuania)

Maxim Pshenichnikov, University of Groningen (Netherlands)

Martin Aeschlimann, Technishe Universität Kaiserslautern (Germany)

Sergey Chekalin, Institute of Spectroscopy (Russian Federation)

ICONO Symposium on Femtosecond Laser Pulse Filamentation

See Leang Chin, Cochair, Laval University (Canada)

Olga Kosareva, Cochair, M.V. Lomonosov Moscow State University (Russian Federation)

ICONO Symposium on THz Technologies and Applications

Bob Miles, Cochair, The University of Leeds (United Kingdom)

Alexander Shkurinov, Cochair, M.V. Lomonosov Moscow State University (Russian Federation)

ICONO Symposium on Organic Photovoltaics

Maxim Pshenichnikov, Cochair, University of Groningen (Netherlands)

Dmitry Paraschuk, Cochair, M.V. Lomonosov Moscow State University

(Russian

Federation)

ICONO/LAT Symposium on 50 Years of Laser Innovations

Alexander Manenkov, Chair, A.M. Prokhorov General Physics Institute (Russian Federation)

ICONO/LAT Symposium on Development of Coherent and Nonlinear Optics in Kazan, Russia

Vitaly Smartsev, Chair, Zavoisky Physical-Technical Institute (Russian Federation) 